\title{
PENGEMBANGAN MEDIA PUPPY BERBASIS ADOBE FLASH CS6 UNTUK PEMBELAJARAN TEOREMA PYTHAGORAS
}

\author{
Benidictus Adhi Cahyanindya ${ }^{1}$, Helti Lygia Mampouw ${ }^{2}$ \\ ${ }^{1,2}$ Universitas Kristen Satya Wacana, Jl.Dipoenegoro 52-60 Salatiga \\ 202014048@student.uksw.edu
}

\begin{abstract}
Digital-based learning media in mathematics offers an encouraging learning experience. This paper aims to describe the development of PUPPY, a puzzle of the Phytagorean theorem, on learning the Phytagorean theorem for 8th grade junior high school students. This research and development applies the 5 phases of ADDIE in generating PUPPY using Adobe Flash CS6. PUPPY is packaged in an interactive animations that are equipped with an evaluation of the understanding of the Pythagorean theorem so as to enables students to do individual evaluation of the achievement of competencies related to the Phytagorean theorem. The structure of the material in PUPPY consists of an explanation of the elements of a right triangle, animation of the discovery of the Pythagorean theorem formula and the application of the formula to a right triangle. The PUPPY test on the $8^{\text {th }}$ grade junior high school students resulted in $80 \%$ of students being motivated to learn, $90 \%$ of students understood the instructions and $90 \%$ of students were helped in understanding the Pythagorean theorem material. Based on these results it can be concluded that the PUPPY is a valid, practical and effective media to help students construct a better understanding of the Pythagorean theorem.
\end{abstract}

Keywords: Learning media, PUPPY, Pythagorean theorem

\begin{abstract}
Abstrak
Pembelajaran matematika berbasis digital model permainan menawarkan pengalaman belajar yang menyenangkan. Makalah ini bertujuan mendeskripsikan pengembangan PUPPY, yakni sebuah puzzle pembuktian teorema Pytagoras, pada pembelajaran teorema Phytagoras untuk siswa kelas VIII SMP. Penelitian pengembangan ini menerapkan 5 fase model pengembangan ADDIE dalam menghasilkan PUPPY menggunakan Adobe Flash CS6. PUPPY dikemas dalam bentuk animasi interaktif yang dilengkapi dengan evaluasi pemahaman teorema Phytagoras sehingga memungkinkan siswa melakukan evaluasi individu atas ketercapaian kompetensi terkait teorema Phytagoras. Struktur materi pada PUPPY terdiri dari penjelasan unsur-unsur segitiga siku-siku, animasi penemuan rumus teorema Pythagoras serta penerapan rumus tersebut pada segitiga siku-siku. Ujicoba PUPPY pada siswa kelas VIII SMP menghasilkan $80 \%$ siswa termotivasi belajar, $90 \%$ siswa memahami petunjuk penggunaan dan $90 \%$ siswa terbantu dalam memahami materi teorema Phytagoras. Berdasarkan hasil tersebut dapat disimpulkan bahwa media PUPPY merupakan media yang valid, praktis dan efektif untuk membantu siswa mengkonstruksi pemahaman yang lebih baik tentang teorema Pythagoras.
\end{abstract}

Kata Kunci : Media Pembelajaran, PUPPY, Teorema Pythagoras

\section{PENDAHULUAN}

Matematika merupakan aktivitas insani yang terkait langsung dengan kehidupan sehari-hari. Matematika merupakan cara berpikir logis yang dipresentasikan dalam bilangan, ruang, dan bentuk dengan aturan-aturan yang telah ada. Membangun rumah, bercocok tanam dan berdagang adalah contoh nyata di dalam kehidupan sehari-hari yang membutuhkan matematika. Pada hakikatnya, konsep di dalam matematika memiliki hubungan dengan kegunaan praktis di dalam kehidupan seharihari.

Teorema Phytagoras adalah salah satu temuan besar pada abad keenam sesudah Masehi. Teorema Pythagoras menyatakan bahwa pada setiap segitiga siku-siku berlaku kuadrat panjang sisi 
Profil Berpikir Reflektif Siswa dalam Menyelesaikan Soal Luas Lingkaran Ditinjau dari Perbedaan Kemampuan

miring (hipotenusa) sama dengan jumlah kuadrat panjang sisi-sisi siku-sikunya. Gambar 1 menampilkan teorema Phytagoras pada segitiga siku-siku. Bilangan a,b dan c disebut tripel Pthytagoras, 3,4,5 dan 5, 12, 13. Penggunaan teorema Pythagoras dapat untuk menentukan panjang sebuah sisi pada segitiga siku-siku jika panjang dua sisi yang lain diketahui.

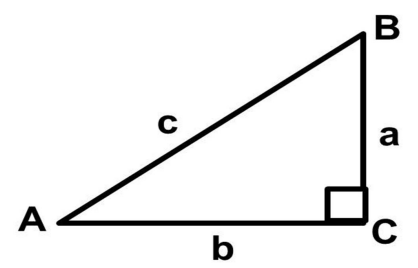

$$
\mathbf{A B}^{2}=\mathbf{A C}^{2}+\mathbf{B C}^{2} \leftrightarrow \mathbf{c}^{2}=\mathbf{a}^{2}+\mathbf{b}^{2}
$$

Gambar 1.Teorema Phytagoras pada segitiga siku-siku

Menurut kurikulum 2013, teorema Pythagoras mulai diajarkan di kelas VIII SMP/MTs. Menurut Permendikbud No. 24 tahun 2016, kemampuan yang diharapkan adalah siswa dapat menjelaskan dan membuktikan teorema Phytagoras dan tripel Phytagoras serta dapat menyelesaikan masalah yang berkaitan dengan teorema Phytagoras dan tripel Phytagoras. Selanjutnya terorema Pythagoras menjadi salah satu materi prasyarat untuk belajar materi lainnya seperti materi segitiga siku-siku, lingkaran, garis singgung lingkaran, bangun ruang sisi lengkung dan lain-lain. Oleh karena itu siswa perlu untuk menguasai teorema Pythagoras.

Siswa yang sudah belajar teorema Phytagoras sering tidak memiliki pemahaman sesuai kompetensi yang diharapkan. Banyak siswa yang masih kesulitan memahami dan menerapkan teorema Phytagroas. Jamilah (2013) menemukan bahwa siswa mengalami kesulitan dalam memahami hubungan sisi miring (hipotenusa) dengan kedua siku-siku sehingga siswa cenderung menghafal rumus teorema Pythagoras. Kondisi tersebut dapat diatasi dengan menggunakan media pembelajaran yang tepat. Rifai (2017) dalam penelitian menyatakan bahwa media Puzzle Pembuktian Pythagoras (PuPPy) dapat digunakan secara praktis dan efektif untuk mengkonstruksi siswa dalam belajar Pythagoras. Siswa yang menggunakan media PuPPy memberikan respon positif terhadap media PuPPy.

Perkembangan pesat dalam bidang teknologi digital mendorong adanya inovasi bidang pendidikan yang memanfaatkan kemajuan tersebut. Media pembelajaran semakin beragam. Seels dan Glasgow (Arsyad, 2013) mengklasifikasikan media pembelajaran ke dalam dua kelompok besar, yaitu media tradisional dan teknologi mutakhir. Salah satu yang termasuk kelompok teknologi mutakhir yaitu media berbasis mikroprosesor. Media berbasis mikroprosesor terdiri dari video, games computer, animasi 2D, animasi 3D, computer-assited instruction. Program yang mampu untuk membuat media berbasis mikroprosesor salah satunya adalah Adobe Flash CS6. Adobe Flash CS6 merupakan software untuk pembuat animasi 2D maupun 3D yang berbentuk flash. Flash dapat 
diaplikasikan untuk pembuatan animasi kartun, animasi interaktif, banner iklan, website, game dan presentasi.

Perangkat lunak yang tersdia banyak memberikan banyak pilihan dalam menghasilkan mediamedia pembelajara berbasis digital. Utami dan Mampouw (2018) menggunakan Autoplay Media Studio dalam menghasilkan Al-Smart, yakni media pembelajaran untuk materi bentuk aljabar di kelas VII SMP. Hasilnya, siswa dapat menikmati belajar matematika dengan lebih baik. Novyarti (2014) menggunakan Adobe Flash dan Autoplay Media Studio dalam pembelajaran inkuiri materi garis dan sudut di kelas VII SMP. Hasilnya adalah terdapat 19 d siswa tuntas belajar dengan nilai tertinggi 100, nilai terendah 66,67 dan KKM sebesar 83,36\%. Anggara (Priyatno, 2011) menyebutkan bahwa Adobe Flash CS6 dapat digunakan lebih mudah dalam membuat media berbasis mikroprosessor. Hal ini dikarenakan Adobe Flash CS6 memilik tampilan, fungsi dan pilihan palet yang beragam, serta kumpulan tool yang sangat lengkap. Bagi seorang pemula yang masih awam terhadap dunia desain dan animasi akan lebih mudah memahami program ini dibanding dengan program jenis lainnya.

Keunggulan Adobe Flash dalam kemudahan penggunaannya dan terdapatnya media pembelajaran teorema Phytagoras berbasis puzzle yang mampu secara praktis dan efektif mengkonstruksi siswa dalam belajar teorema Phytagoras mendorong peneliti untuk mengembangkan media pembelajaran berbasis Adobe Flash Cs6 dalam mengembangkan media pembelajaran digital pada materi teorema Phytagoras. Media pembelajaran yang dikembangkan dinamakan PUPPY. Makalah ini bertujuan mendeksripsikan pengembangan media pembelajaran PUPPY pada materi teorema Pythagoras untuk siswa kelas VIII SMP.

\section{METODE}

Penelitian ini merupakan penelitian pengembangan. Penelitian pengembangan adalah metode penelitian yang digunakan untuk menghasilkan produk tertentu dan menguji keefektifan produk tersebut (Sugiyono, 2012). Penelitian pengembangan ini menggunakan model ADDIE yang terdiri dari 5 tahap yaitu analisis (analyze), perancangan (design), pengembangan (develop), implementai (implement) dan evaluasi (evaluate) yang disingkat ADDIE (Branch, 2014). Chaeruman (2008) menulis kelima fase sebagai berikut: (1) Analisis, tahap untuk menentukan masalah dan solusi yang tepat dan menentukan kompetensi siswa, (2) Perancangan, tahap untuk menentukan kompetensi khusus, metode, bahan ajar, dan strategi pembelajaran, (3) Pengembangan, tahap untuk memproduksi program dan bahan ajar yang akan digunakan dalam program pembelajaran, (4) Implementasi, tahap untuk melaksanakan program pembelajaran dengan menerapkan desain atau spesifikasi program pembelajaran dan (5) Evaluasi , tahap evaluasi dilaksanakan dalam dua hal yaitu menilai hasil belajar siswa dan mengevaluasi media. Kelima fase tersebut perlu dilakukan secara sistemik dan sistematik (Benny A. Pribadi,2016).

Kelebihan dari model ADDIE yaitu: (1) memperhatikan perkembangan ranah kognitif, afektif, dan psikomotor siswa, (2) bersifat konsisten dan reliabel, (3) saling ketergantungan satu sama 
Profil Berpikir Reflektif Siswa dalam Menyelesaikan Soal Luas Lingkaran Ditinjau dari Perbedaan Kemampuan

lain, sehingga tidak ada unsur-unsur yang terpisah dari sistem, dan (4) sederhana dan terstruktur dengan sistematis sehingga model desain ini akan mudah dipelajari oleh para pendidik (Sugiyono, 2009).

Media pembelajaran yang dikembangkan dinamakan PUPPY untuk pembelajaran materi teorema Pythagoras sub materi menemukan teorema Pythagoras. PUPPY dibuat menggunakan aplikasi software Adobe Flash CS6. Media ini dikembang dalam bentuk semi interaktif di mana ada komunikasi antara pengguna dan media PUPPY. Selain pengguna media ini mengamati dan mempelajari apa yang disajikan, juga terdapat bahan evaluasi atas pengetahuan tentang Teorema Pythagoras sub materi menemukan teorema Pythagoras. Validasi media ini dilakukan untuk memperoleh penilaian mengenai tampilan dan cangkupan materi yang disajikan.hasil penilaian dari reviewer digunakan pedoman untuk revisi sehingga nantinnya akan dihasilkan media yang layak uji coba baik dari segi tampilan maupun materi. Uji coba dilakukan pada skala terbatas. Media ini diutamakan untuk siswa kelas VIII SMP tetapi tidak tertutup kemungkinan digunakan pada level yang lain.

\section{HASIL}

Hasil pengembangan media pembelajaran PUPPY berdasarkan tahapn ADDIE dijelaskan dideskripsikan berikut ini.

Analisis

Pada tahap ini dilakukan analisis kebutuhan awal dalam mengembangkan media pembelajaran yang meliputi analisis kurikulum, analisis karakteristik siswa dan analisis media yang akan digunakan dalam mengembangkan media ini. Peneliti mengumpulkan informasi yang diperlukan siswa SMP kelas VII dalam pembelajaran matematika. Berdasarkan telaah hasil-hasil penelitian, wawancara dengan beberapa guru matematika dan siswa diperoleh daftar topik-topik yang sulit dimengerti siswa dan ada juga yang sulit diajarkan guru. Topik-topik tersebut adalah sebagai berikut:

a. Aljabar pada kelas VII semester 1 .

b. Perbandingan garis dan sudut pada kelas VII semester 2 .

c. Persamaan garis pada kelas VIII semester 1.

d. Teorema Pytagoras kelas VIII semester 1.

Dari keempat materi yang sulit tersebut, siswa lebih sulit memahami materi Teorema Pytagoras. Siswa masih kesulitan untuk mencari suatu sisi dilakukan dengan menjumlah atau mengurangkan, jika mengurangkan mana yang harus dikurangi. Hal itu salah satunya dapat diakibatkan karena tidak diberikannya kesempatan siswa untuk menemukan rumus tersebut, sehingga daya ingat siswa akan rumus tersebut tidak maksimal. Siswa mengetahui rumus tersebut hanya dari mendengarkan penjelasan guru ataupun membaca di buku. Siswa tidak diberi kesempatan untuk membuktikan secara langsung. 
Perkembangan jaman saat ini teknologi elektonik berkembang sangat pesat, salah satu diantaranya adalah komputer. Komputer adalah satu perangkat pengolah data yang dapat didesain dan dikembangkan untuk membantu manusia dalam menjalankan aktivitasnya. Teknologi informasi penggunaan komputer telah merambah kesegala bidang kehidupan, termasuk dalam dunia pendidikan. Komputer memiliki program atau aplikasi praktis yang dapat dimanfaatkan dan dikembangkan untuk pendidikan. Orientasi penggunaan komputer dalam dunia pendidikan adalah bagaimana komputer dapat membantu orang dalam proses pembelajaran, seperti presentasi mengajar, pengembangan bahan atau meteri pembelajaran dan sebagai alternatif sumber belajar kepada peserta didik.

Penggunaan komputer dalam proses pembelajaran dapat melahirkan suasana yang menyenangkan karena peserta didik dapat mengendalikan kecepatan belajar sesuai dengan kemampuannya, tidak cepat bosan dan menjadi tekun, sehingga diharapkan siswa menjadi lebih unggul di bidangnya.Program atau aplikasi yang saat ini sering digunakan dalam proses pembelajaran adalah power point, tetapi tampilan pada power point yang dapat digunakan sangat terbatas.Guna menambah variasi yang lebih menarik dalam proses pembelajaran, peneliti mencoba memperkenalkan adobe flash cs6 dalam pembelajaran. Guna mengubah paradigma siswa bahwa pelajaran teorema Pytagoras itu sulit dan tidak menarik, maka peneliti mendisain media pembelajaran berbasis komputer yang Menggunakan Adobe Flash CS6 untuk materi penemuan teorema Pytagoras yang diberi nama PUPPY.

\section{Perancangan}

Pada tahap ini peneliti menentukan unsur-unsur yang akan dimuat dalam media pembelajaran yang akan dikembangkan. Peneliti membuat storyboard yang merupakan garis besar isi media secara umum yang meliputi desain template dan materi. Selain itu, penentuan alur pembelajaran yang akan dibuat serta merencanakan isi dalam penyajian materi.

Pada tahap ini peneliti melaksanakan perancang media pembelajaran yang akan digunakan yaitu pembelajaran dengan media komputer. Materi yang akan dibuat adalah materi menemukan teorema Pythagoras yang meliputi materi ajar dan latihan soal, karena siswa masih banyak yang mengalami kesulitan pada materi teorema Pythagoras. Media pembelajaran dengan menggunakan komputer yang akan digunakan adalah aplikasi software Adobe Flash CS6 yang diberi nama PUPPY. Adobe Flash CS6 dapat bekerja pada Windows XP, Windows 7, Windows Vista, ataupun Windows 8. Agar fitur Flash dan SWF dapat berjalan dengan baik di Adobe Flash CS6, maka software Flash Player dan Flash Player X harus terinstal pada komputer.

Media ini didisain terbagi atas 2 bagian yaitu tampilan dan isi. Berikut uraian dari kedua bagian tersebut.

\section{Tampilan}

Tampilan media pembelajaran akan menggunakan susunan warna yang cerah dan dibuat agar menarik bagi siswa. Sistem navigasi juga dibuat secara sederhana dan mudah dioperasikan oleh siswa. 
Profil Berpikir Reflektif Siswa dalam Menyelesaikan Soal Luas Lingkaran Ditinjau dari Perbedaan Kemampuan

Isi

Media pembelajaran ini akan terdiri dari beberapa bagian guna memenuhi kebutuhan yang diperlukan. Materi Pembelajaran terdiri atas penjelas singkat tentang sisi-sisi segitiga, animasi penemuan rumus teorema Pythagoras serta penerapan rumus pada segitiga siku-siku. Selanjutnya didisain bentuk permainan. Permaian terdiri dari model puzzle. Permainan ini digunakan untuk mengemas drill latihan soal agar lebih menarik. Pada games puzzle, siswa dituntut untuk menyusun susunan potongan puzlle dari dua buah persegi pada sisi-sisi siku-siku dan menyuusun pada persegi besar pada sisi miring segitiga siku-siku. Sebagai evaluasi dari penggunaan media pembelajaran ini maka diperlukan latihan soal. Latihan soal akan terdiri dari soal-soal menjodohkan yang dikemas ke dalam games seperti konsep memasangan jawaban dengan soal. Soal-soal nantinya terkait tentang penerapan rumus pytagoras untuk mencari panjang salah satu sisi segitiga siku-siku.

\section{Pengembangan}

Tahap ini merupakan proses pembuatan media pembelajaran itu sendiri. Pada tahap ini, peneliti melanjutkan pembuatan media beradasrkan storyboard dan desain yang telah dibuat. Selain itu hal-hal yang dilakukan antara lain: pengetikan materi dan naskah-naskah soal latihan, pembuatan animasi, gambar, tombol navigasi, pembuatan game, video dan pemberian musik.

Tahap ini adalah untuk menghasilkan program dan bahan ajar berupa media pembelajaran dengan materi menemukan Teorema Pythagoras yang dapat digunakan secara mandiri. Pengembangan media pembelajaran ini terdiri dari beberapa tahap yang meliputi penyusunan desain media pembelajaran dilanjutkan pembuatan media pembelajaran, dan tahap penyelesaian dengan mengecek kesalahanan-kesalahan pada media pembelajaran. Adapun hasil dari tahap pengembangan media pembelajaran sebagai berikut:

\section{Tampilan media pembelajaran}

Tampilan berupa menu, navigasi bertujuan untuk membuat media pembelajaran menjadi lebih menarik. Tampilan dapat dilihat pada Gambar 2.
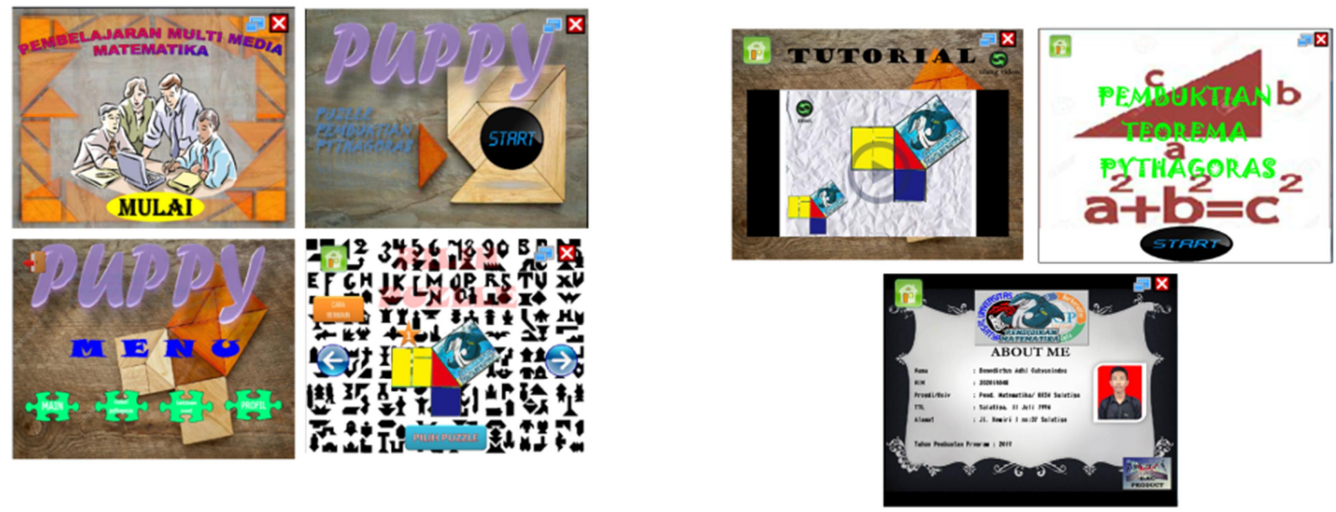

Gambar 2. Tampilan Media Pembelajaran 
Isi

\section{Materi Pembelajaran}

Materi Pembelajaran yaitu terdiri atas 3bagian penting yaitu penjelas singkat tentang penyebutan sisi-sisi pada segitiga, animasi penemuan rumus teorema Pythagoras serta penerapan rumus teorema pythagoras pada segitiga siku-siku. Tampilan materi pembelajaran dapat dilihat Gambar 3.

\section{Permainan}

Permainan terdiri dari 1 jenis games, yaitu puzzle. Pada games puzzle, disediakan susunan puzlle pada persegi sedang kan kecil pada sisi bagian siku-suku, siswa dituntut untuk menyusun puzlle pada persegi besar pada sisi miring/hypotenuse dengan penempatan secara tepat di setiap stage. Pada game ini terdiri dari 10 stage atau bagian. Setiap bagian memiliki variasi bentuk dan tingkat kepingan puzlle yang berbeda-beda. Tampilan games puzzle dan dapat dilihat pada Gambar 4 .
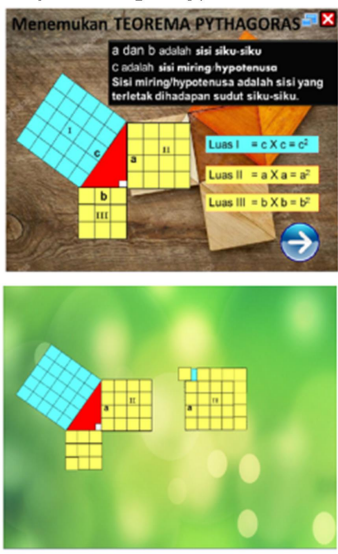
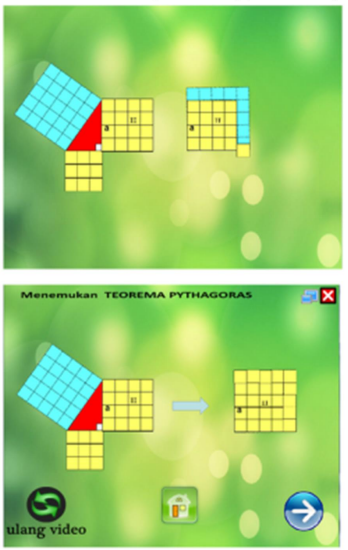
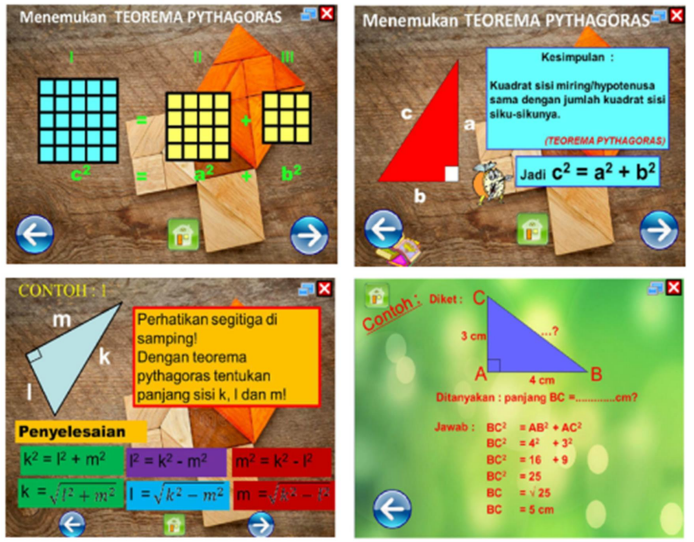

Gambar 3. Tampilan Materi Pembelajaran
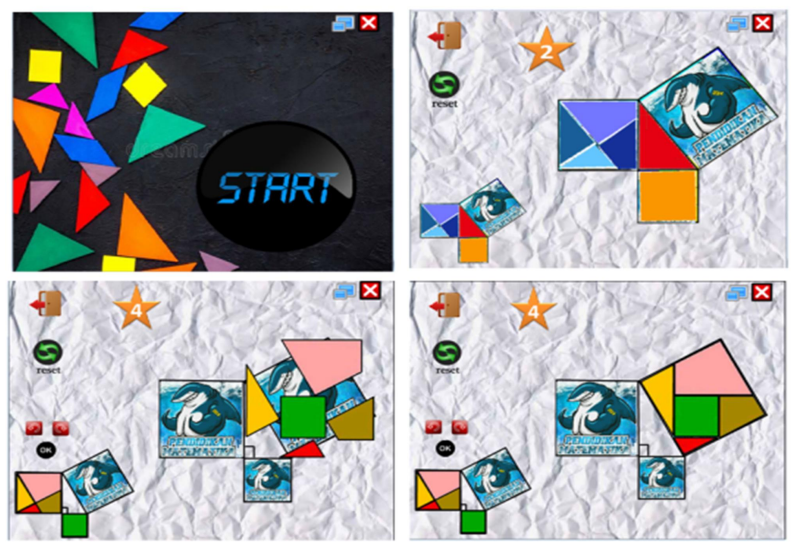

Gambar 4. Tampilan Games Puzzle 
Profil Berpikir Reflektif Siswa dalam Menyelesaikan Soal Luas Lingkaran Ditinjau dari Perbedaan Kemampuan

\section{Latihan Soal}

Latihan soal terdiri dari soal-soal menjodohkan sebanyak 9 butir soal yang dikemas ke dalam games. Setiap soal memiliki 3 jawaban benar dan tiga jawaban salah. Jika pemain menjodohkan dengan jawaban yang salah jawaban akan kembali ke tempat semula. Soal-soal mencakup materi tentang penerapan rumus pytagoras untuk mencari panjang salah satu sisi segitiga siku-siku. Tampilan kuis dapat dilihat pada Gambar 5.

Aplikasi yang telah dikembangkan selanjutnya dinilai oleh ahli media dan ahli materi. Penilaian ini bertujuan untuk mendapatkan kritik dan saran yang berguna dalam perbaikan media pembelajaran berbasis aplikasi android sebelum diterapkan dalam pembelajaran. Hasil penilaian oleh ahli media diperoleh skor rata-rata 34,33 dan persentase $86 \%$ yang termasuk dalam kategori sangat baik. Adapun hasil penilaian oleh ahli materi diperoleh skor rata-rata 40,67 dan persentase $81 \%$ yang termasuk dalam kategori sangat baik, sehingga media valid untuk digunakan.

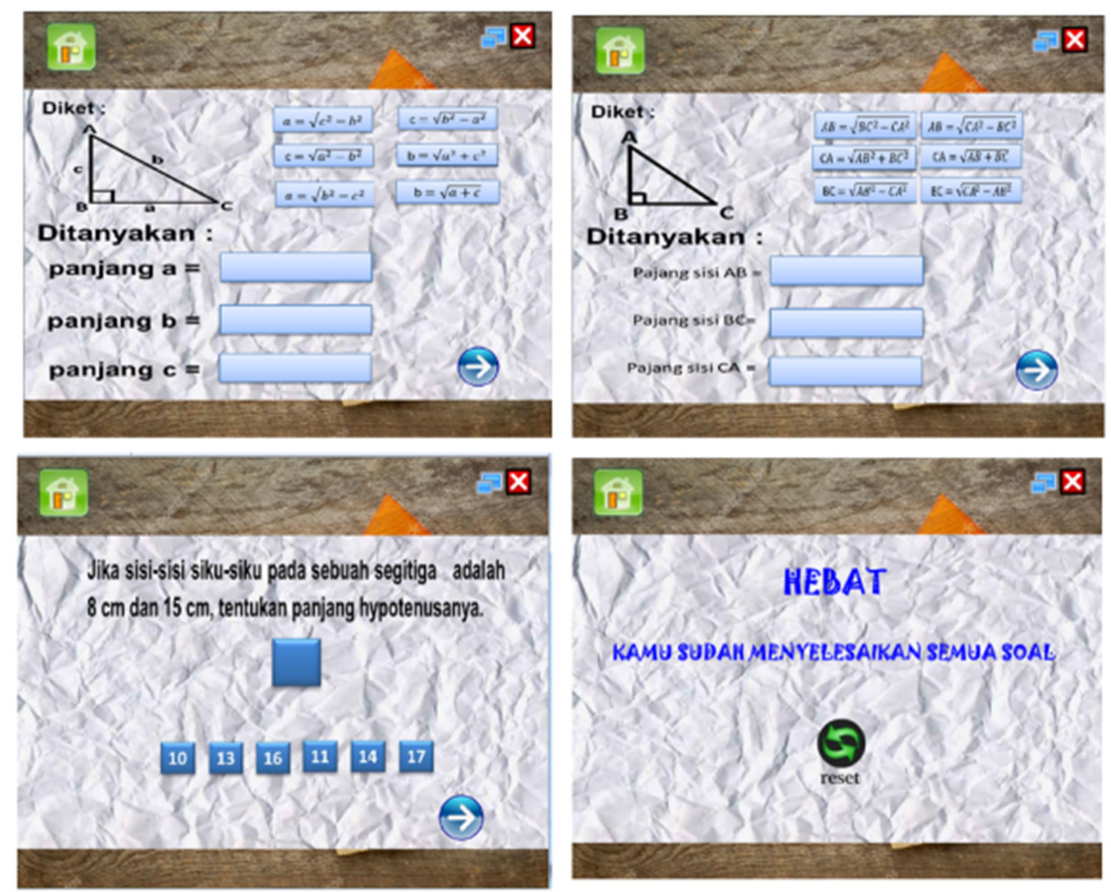

Gambar 5. Tampilan Latihan Soal

\section{Implementasi}

Pada tahap ini peneliti melakukan uji coba media pembelajaran PUPPY. Uji coba dilakukan kepada siswa SMP. Hal tersebut dimaksudkan untuk mengetahui segi kepraktisan pengoperasian media pembelajaran, respon mahasiswa dan siswa terhadap media yang digunakan, dan layak tidaknya media pembelajaran Matematika tersebut dapat meningkatkan kemampuan siswa dalam pembelajaran teorema Pytagoras. Uji coba terbatas PUPPY dilakukan pada siswa kelas VIII SMP secara mandiri yang melibatkan 10 siswa yang memiliki kemampuan yang bervariasi. Kegiatan pembelajaran dilaksanakan secara langsung datang kerumah siswa. Mengawali penggunaan aplikasi PUPPY ini siswa diberi petunjuk cara menggunakan media pembelajaran PUPPY. Ada siswa yang 
langsung mengerti dan masih ada yang bertanya ketika menggunakan media. Siswa yang masih bertanya ketika sudah mencoba beberapa tahapan siswa tersebut bisa menggunakan sendiri. Siswa tertarik dalam menggunakan media pembelajaran PUPPY dan siswa mudah menggunakan media pembelajaran PUPPY.

\section{Evaluasi}

Pada tahap ini peneliti mengobservasi kinerja media pembelajaran PUPPY dan melakukan perbaikan media agar layak digunakan. Berdasarkan hasil angket tertutup tentang media pembelajaran PUPPY diperoleh penggunaan media pembelajaran PUPPY asyik dimainkan sebesar $90 \%$ setuju dan animasi dalam media pembelajaran PUPPY menarik sebesar $80 \%$ setuju yang berarti motivasi siswa dalam menggunakan media PUPPY sebesar 95\% setuju. Media pembelajaran PUPPY dapat digunakan dengan mudah sebesar $90 \%$ setuju dan petunjuk penggunaan media ini mudah dipahami sebesar 90\% setuju yang berarti dalam penggunaan media pembelajaran PUPPY mudah digunakan sebesar $85 \%$ setuju. Siswa merasa terbantu dengan adanya media pembelajaran PUPPY sebesar $85 \%$ setuju, media pembelajaran PUPPY membantu siswa dalam memahami materi penemuan teorema Pythagoras sebesar 90\% setuju, dan media pembelajaran PUPPY membantu siswa dalam pemantapan latihan soal sebesar 85\% setuju yang berarti media pembelajaran PUPPY dapat membantu siswa dalam pembelajaran penemuan teorema Pythagoras sebesar $90 \%$ setuju. Dengan demikian dapat disimpulkan bahwa pengembangan media PUPPY untuk penemuan Teorema Pythagoras, penggunaan media pembelajaran PUPPY mudahan digunakan sebesar 90\% setuju, dan pembelajaran PUPPY dapat membantu siswa dalam pembelajaran penemuan Teorema Pythagoras sebesar 90\% setuju.

\section{KESIMPULAN}

Produk yang dihasilkan dalam penelitian ini adalah media pembelajaran matematika pada materi Teorema Pythagoras untuk siswa kelas VIII SMP. Media pembelajaran ini dikembangkan dengan bantuan software Adobe Flash CS6. Penelitian ini menggunakan model pengembangan ADDIE yang terdiri dari lima langkah penelitian yaitu analisis, perancangan, pengembangan, implementasi dan evaluasi. Dari media PUPPY yang telah divalidasi terdapat ujicoba PUPPY pada siswa kelas VIII SMP yang menghasilkan $80 \%$ siswa termotivasi belajar, 90\% siswa memahami petunjuk penggunaan dan 90\% siswa terbantu dalam memahami materi teorema Phytagoras. Berdasarkan hasil tersebut dapat disimpulkan bahwa media PUPPY merupakan media yang valid, praktis dan efektif untuk membantu siswa mengkonstruksi pemahaman yang lebih baik tentang teorema Pythagoras.

\section{DAFTAR PUSTAKA}

Adinawan, Sugiono. (2006). Matematika SMP Jilid 2A Kelas VIII. Jakarta: PT. Gelora Aksara Pratama

Arsyad, Azhar. (2013). Media Pembelajaran. Jakarta: Rajagrafindo Persada. 
Profil Berpikir Reflektif Siswa dalam Menyelesaikan Soal Luas Lingkaran Ditinjau dari Perbedaan Kemampuan

Branch, RM, \& Kopcha, TJ. (2014) . model desain pembelajaran. Dalam Handbook penelitian tentang komunikasi pendidikan dan teknologi.

Chaeruman. (2008). Mengembangkan Sistem Pembelajaran dengan Model ADDIE. Jakarta: PT Remaja Rosdakarya.

Daulay, Jamilah. (2013). Upaya Meningkatkan Hasil Belajar Siswa Dengan Model Pembelajaran Langsung Menggunakan Macromedia Flash 8 Pada Materi Teorema Pythagoras Di Kelas VIII Smp N 35 Medan Tahun Ajaran 2012/2013. Undergraduate thesis, UNIMED.

Hidayatullah, Priyatno. (2011). Animasi Pendidikan Menggunakan Flash. Bandung : Informatika Husain Tampomas. (2005). Matematika 2 untuk SMP Kelas VIII. Yudistira: Jakarta

Katz, Victor J. (2009). A History of Mathematics An Introduction. University of the District of Columbia

Mas’ud Rifai. (2017). Pengembangan Media Puzzle Untuk Pembuktian Teorema Pythagoras.jurnal online (http://eprints.umpo.ac.id/1810/1/HALAMAN\%20DEPAN.pdf) diakses 10 Maret 2016

Novyarti, Elsa. (2014). Pengembangan Media Pembelajaran Menggunakan Adobe Flash dan Autoplay Media Studio dalam Pembelajaran yang Berbasis Inquiry pada Materi Garis dan Sudut Kelas VII SMP. Jurnal Edumatica. journal.unja.ac.id/index.php/edumatica/ article/view/2073) diakses 9 Maret 2017.

Permendikbud. (2016). Peraturan Menteri Pendidikan Dan Kebudayaan Nomor 24 Tahun 2016 Tentang Kompetensi Inti Dan Kompetensi Dasar Pelajaran Pada Kurikulum 2013 Pada Pendidikan Dasar Dan Pendidikan Menengah.

Pribadi, Benny A. (2016). Model Desain Sistem Pembelajaran.Jakarta : Dian Rakyat

Sugiyono. (2009). Metode Penelitian Pendidikan. Bandung: Alfabeta.

Sugiyono. (2012). Metode Penelitian Kuantitatif Dan R\&D. Bandung: Alfabeta.

Utami, D. W., \& Mampouw, H. L. (2018). Pengembangan media pembelajaran Al-Smart untuk Materi Operasi pada Bentuk Aljabar. Prosiding Seminar Nasional Matematika Dan Pendidikan Matematika, 421-427. 